\title{
First report of Fusarium proliferatum causing root rot of Gerbera in China
}

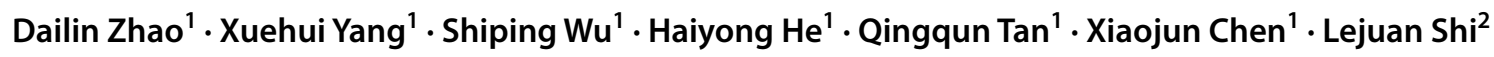

Received: 14 July 2019 / Accepted: 4 October 2019 / Published online: 22 October 2019

(c) The Author(s) 2019

\begin{abstract}
In January 2018, gerbera plants showed root rot symptoms were found in a greenhouse at Guizhou Horticultural Institute in Guiyang city, Guizhou Province in southwest China. Morphological and molecular identifications confirmed the isolation of Fusarium proliferatum. The pathogenicity was verified with Koch's postulates. To our knowledge, this is the first report confirming root rot of gerbera caused by Fusarium proliferatum in China.
\end{abstract}

Keywords Fusarium proliferatum $\cdot$ Gerbera $\cdot$ Root rot · China

Gerbera (Gerbera jamesonii, family Asteraceae), also known as Transvaal Daisy, Barberton Daisy or African Daisy, is the fifth most popular cut flowers and potted plants with great commercial value around the world (Terri et al. 2006; Bhatia et al. 2009). Gerbera is a genus of \pm 30 species of perennial herbs distributed largely through Africa, Madagascar and extending into China (Hind 2007).

In the winter of 2018 , we noticed approximately $30 \%$ of gerbera plants showed the root rot symptoms in a greenhouse located at Guizhou Horticultural Institute in Guiyang city, Guizhou Province in southwest China. In the advanced stage of the disease, the roots, crown and stems of these plants were all in black and rotten, with their epidermis peeling off. The leaves and stems of infected plants were chlorotic and wilted.

Diseased root pieces $(3 \times 3 \mathrm{~mm})$ of gerbera plants were surface-disinfected with $75 \%$ ethanol for $30 \mathrm{~s}$ and $0.5 \%$ $\mathrm{NaClO}$ for $3 \mathrm{~min}$ and washed three times with sterilized water. The disinfected pieces were dried and incubated on potato dextrose agar (PDA) at $25^{\circ} \mathrm{C}$ for 7 days inside a dark chamber.

Xuehui Yang

yxuehui66@163.com

$\triangle$ Lejuan Shi

lejuan2003@163.com

1 Institute of Plant Protection, Guizhou Academy of Agricultural Sciences, Guiyang, China

2 Institute of Horticulture, Guizhou Academy of Agricultural Sciences, Guiyang, China
After incubation, on PDA, colonies of isolated fungi were white mycelium initially and gradually turned violet with aging (Fig. 1a, b). Hyphae were septate and lightly constricted at the septa (Fig. 2a); sterile coiled hyphae were observed (Fig. 2b). Microconidia were abundant, usually nonseptate, occasionally septate, oval, club-shaped or kidney-shaped, measuring 6 to $10 \times 2$ to $4 \mu \mathrm{m}$ (average $7.6 \times 3.0 \mu \mathrm{m}, n=100$ ) (Fig. $2 \mathrm{~g}$ ). Macroconidia were sparse, sickle-shaped, 3 to 5 septate, thin-walled with a tapering and curved apical cell and a well-developed foot cell, measuring 20 to $47 \times 3.6$ to $7.4 \mu \mathrm{m}$ (average $25.3 \times 5.3 \mu \mathrm{m}, n=100$ ) (Fig. 2f, g). Conidiophores formed in moderate-length chains or false heads originated from monophialides and multiphialides (Fig. 2c-e, h-k). This species could produce a lot of moderate-length chains and the number of false heads which were relatively small. Chlamydospores were absent. Morphological characteristics matched $F$. proliferatum (Zhang et al. 2013).

In order to confirm the morphological identification at species level, a single-spore culture (Leslie and Summerell 2006) of strain (named FZJf3-1) was subjected to a genomic DNA extraction and gene amplification. The translational elongation factor $1 \alpha$ (TEF- $1 \alpha)$ region was amplified with PCR using the primer pairs TEF1-728F (5'-CATCGA GAAGTTCGAGAAGG-3') and TEF1-rev (5'-GCCATC CTTGGAGATACCAGC-3') (Carbone and Kohn 1999), and internal transcribed spacer (ITS) region was amplified using the primer pairs ITS1 (5'-TCCGTAGGTGAACCT GCGG-3') and ITS4 (5'-TCCTCCGCTTATTGATATGC $-3^{\prime}$ ) (White et al. 1990). PCR products were sequenced, and 

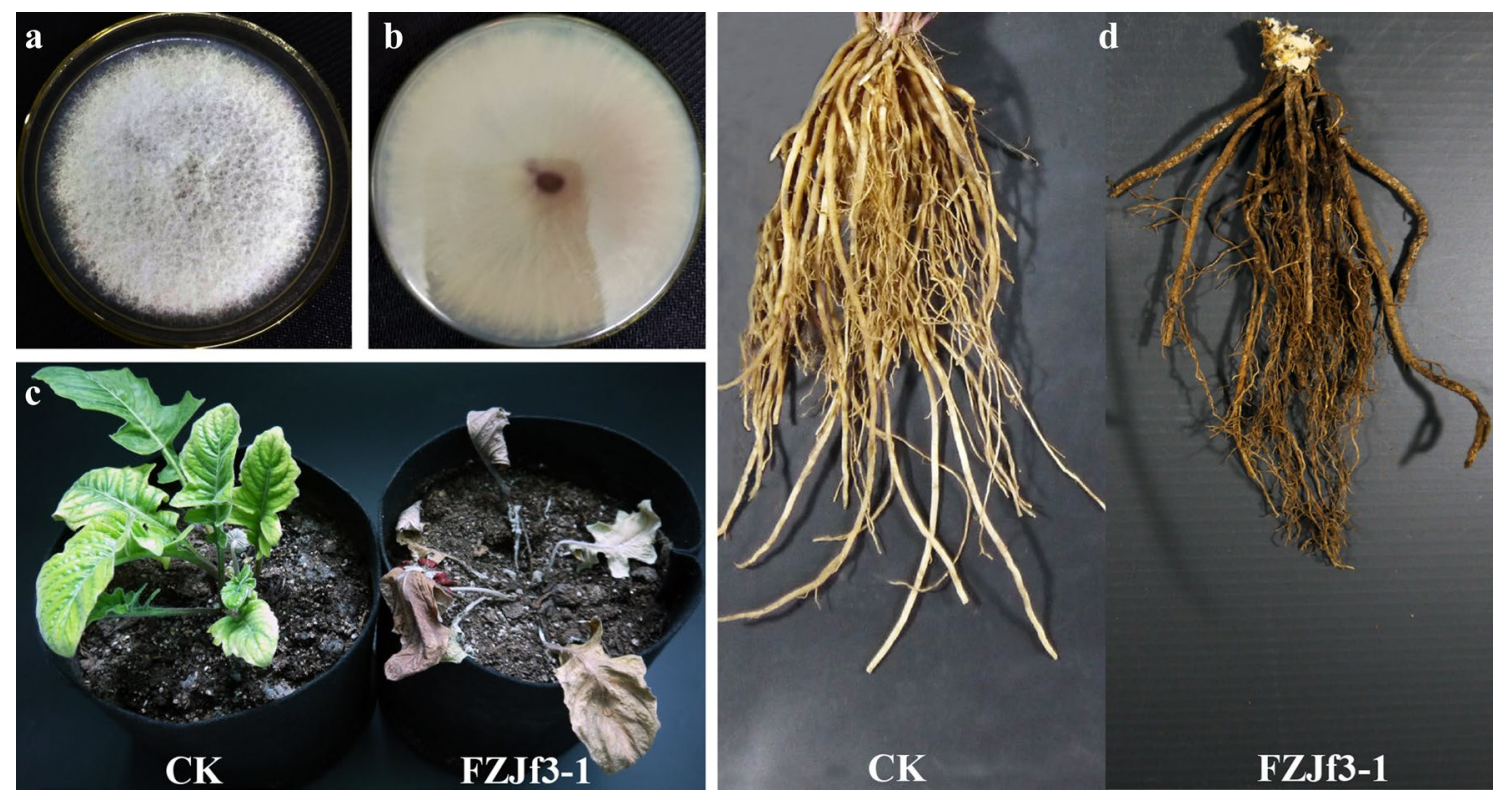

Fig. 1 Colony morphologies on PDA and pathogenicity tests on gerbera plants of isolate FZJf3-1. a, b Colony morphologies on PDA of isolates FZJf3-1. c, d After 49 days, the plants' leaves and stems were

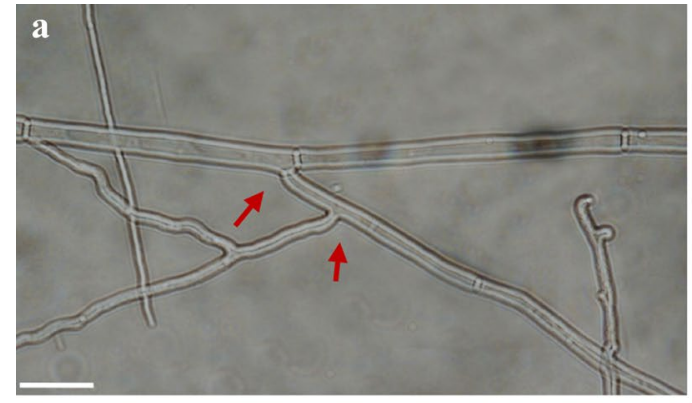

chlorotic and wilted, and roots and crown were all black and rotten in inoculated pots of inoculation of isolates FZJf3-1
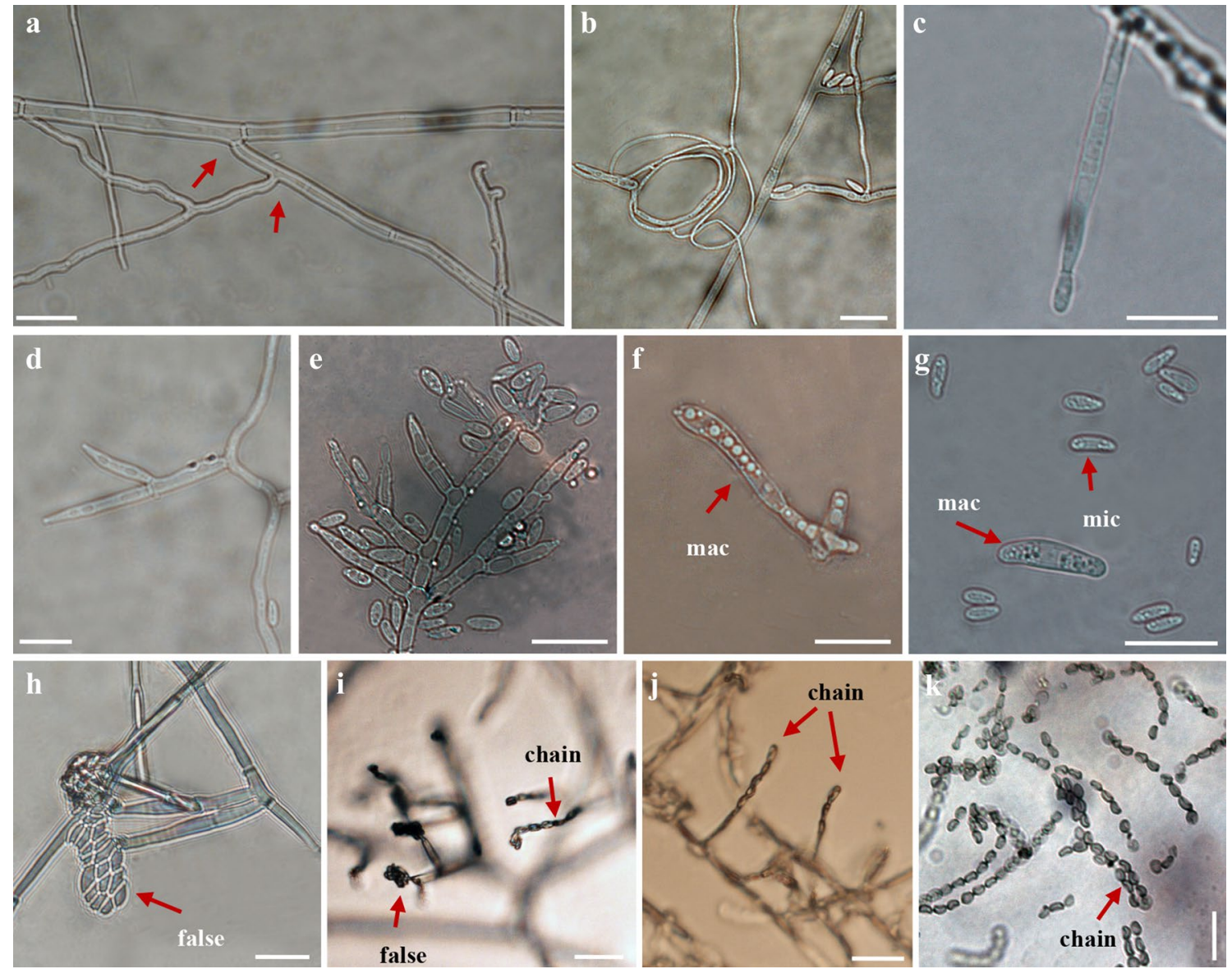

Fig. 2 Morphological characteristics of isolate FZJf3-1. a Hyphae (arrow showing lightly constricted at the septa), b coiled hyphae, c monophialides, $\mathbf{d}$ double monophialides, e multiphialides, $\mathbf{f}, \mathbf{g}$ macro-

conidia (mac) and microconidia (mic), h, $\mathbf{i}, \mathbf{j}, \mathbf{k}$ false heads (false) or moderate-length chains (chain) of microconidia on phialides (arrow). Bars $=20 \mu \mathrm{m}$ 
Fig. 3 Phylogenetic tree produced from the TEF1- $\alpha$ gene sequences showing the phylogenetic relationships among Fusarium spp., using the neighbor-joining method. Relevant bootstrap values (expressed as a percentage of 1000 replicates) are shown at branch points. Bar (0.05) changes per sequence position

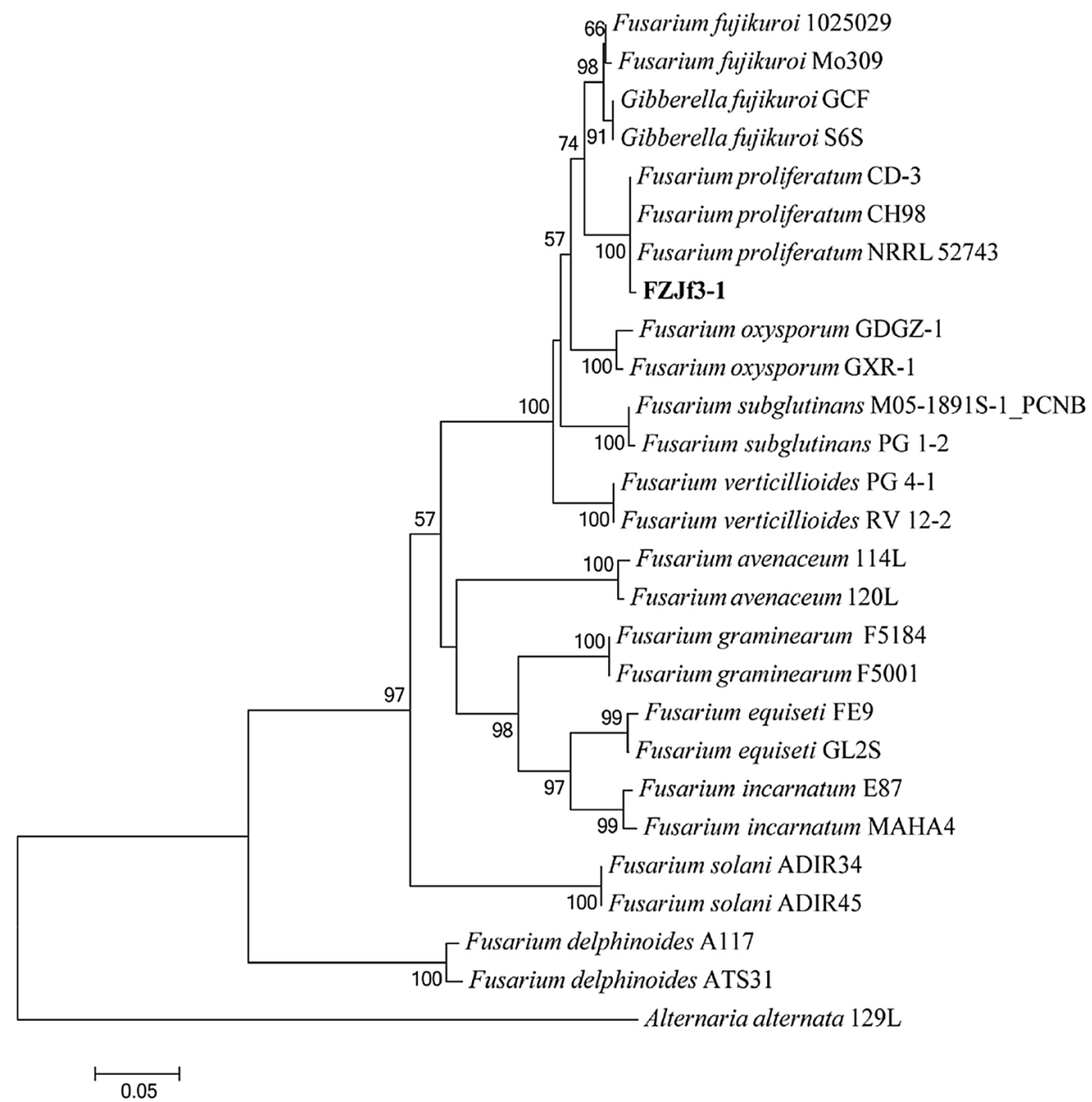

the sequences were compared against the GenBank nucleotide database by using the BLAST alignment. The TEF- $1 \alpha$ sequence showed $100 \%$ identity with all $F$. proliferatum (F. proliferatum strain NRRL 52743(JF740819.1), F. proliferatum strain CH98 (KU939029.1) and $F$. proliferatum strain CD-3 (KU939025.1)) (Fig. 3), and the ITS sequence showed $100 \%$ identity with all $F$. proliferatum $(F$. proliferatum strain MA84 (JQ693101.1) and $F$. proliferatum strain CH98 (KU939077.1)) (Fig. 4).

The TEF- $1 \alpha$ and ITS sequences of this isolate were deposited in GenBank database with accession Nos. MH712884 and MH715405, respectively.

Koch's postulates were checked by using 1-month-old gerbera healthy plants under controlled conditions. F. proliferatum strain FZJf3-1 inoculum $\left(1 \times 10^{6}\right.$ conidia/ml in sterile distilled water) was produced from PDA cultures, and a $25 \mathrm{ml}$ suspension was used to inoculate five potted plants which were grown in sterilized soil. Control plants were inoculated with sterile distilled water. They were incubated at $28^{\circ} \mathrm{C}$ and a $12: 12$ dark/light photoperiod. After 49 days, plants with root rot, leaf and stem chlorosis were observed in inoculated pots while control plants inoculated with sterile water did not show any of the disease symptoms (Fig. 1c, d). F. proliferatum was reisolated from the symptomatic tissues of infected plants and shown to be genetically identical to the original inoculated strain FZJf3-1, fulfilling Koch's postulates.

So far, in China, the main Fusarium pathogens causing root rot are reported by the complex of the $F$. oxysporum and $F$. solani species. In this study, we found that the gerbera root rot was due to $F$. proliferatum. $F$. proliferatum is a cosmopolite saprophytic species, but it is also known to be a pathogen causing root rot on garlic (Leyronas et al. 2018), codonopsis (Gao et al. 2017), alfalfa (Cong et al. 2016.), soybean (Díaz Arias et al. 2011) and blueberry (Pérez et al. 2011). To our knowledge, this is the first report confirming root rot of gerbera caused by $F$. proliferatum in China. 
Fig. 4 Phylogenetic tree produced from the ITS gene sequences showing the phylogenetic relationships among Fusarium spp., using the neighbor-joining method. Relevant bootstrap values (expressed as a percentage of 1000 replicates) are shown at branch points. Bar (0.05) changes per sequence position

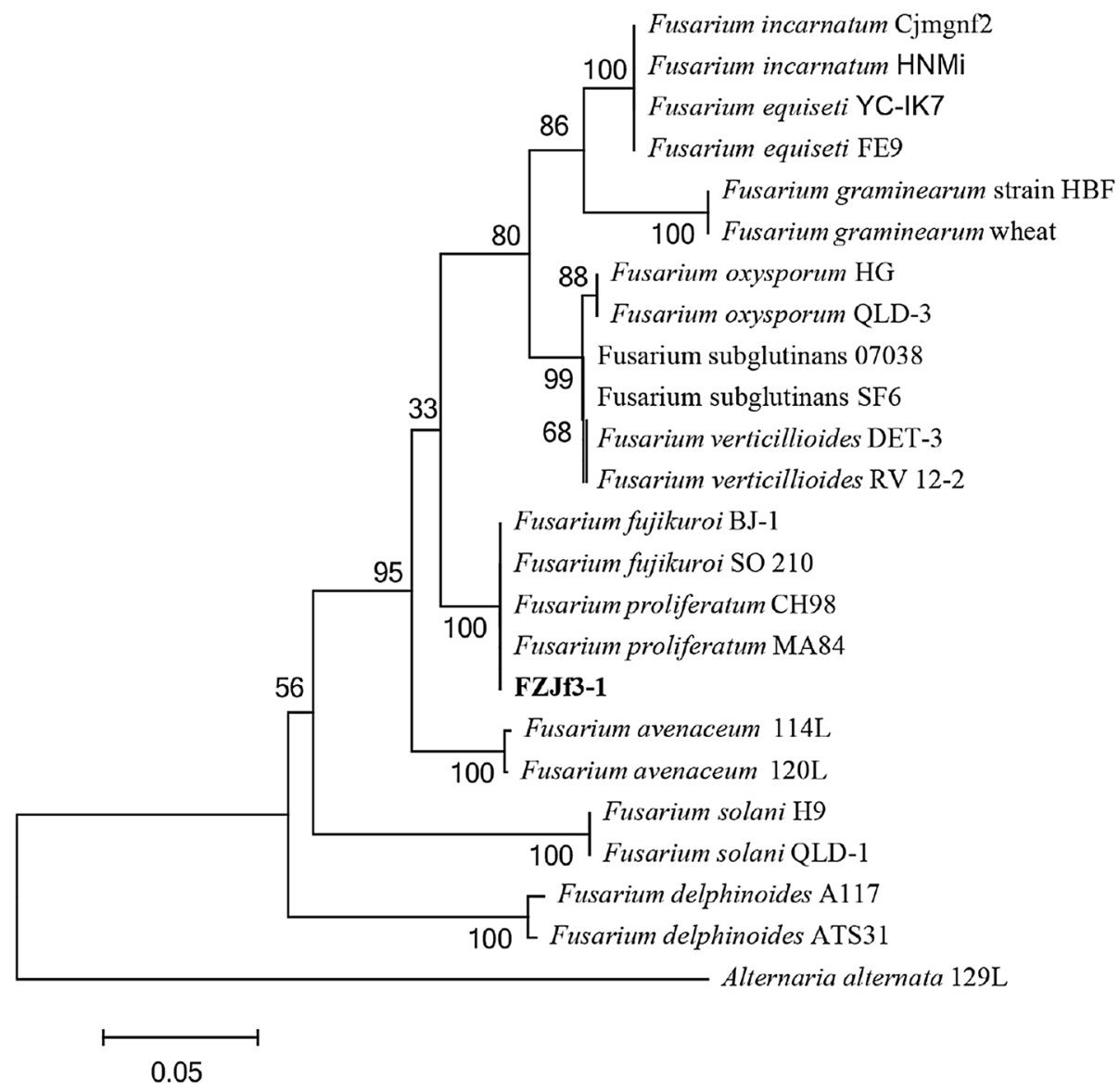

\section{Compliance with ethical standards}

Conflict of interest The authors declare that they have no conflict of interest.

Open Access This article is distributed under the terms of the Creative Commons Attribution 4.0 International License (http://creativeco mmons.org/licenses/by/4.0/), which permits unrestricted use, distribution, and reproduction in any medium, provided you give appropriate credit to the original author(s) and the source, provide a link to the Creative Commons license, and indicate if changes were made.

\section{References}

Bhatia R, Singh KP, Jhang T et al (2009) Assessment of clonal fidelity of micropropagated gerbera by ISSR markers. Sci Hortic Amst 119:208-211

Carbone I, Kohn LM (1999) A method for designing primer sets for speciation studies in filamentous ascomycetes. Mycologia 91:553-556

Cong LL, Sun Y, Kang JM et al (2016) First report of root rot disease caused by Fusarium proliferatum on alfalfa in China. Plant Dis 100(12):2526

Díaz Arias MM, Munkvold GP, Leandro LF (2011) First report of Fusarium proliferatum causing root rot on soybean (Glycine max) in the United States. Plant Dis 95(10):1316
Gao J, Wang J, Yang C et al (2017) Fusarium proliferatum, a new pathogen causing Codonopsis lanceolata root rot in China. Plant Dis 101(9): 1679

Hind DJN (2007) Compositae: II Tribe Mutisieae. In: Kadereit JW, Jeffrey C (eds) The families and genera of vascular plants VIII flowering plants. Eudicots: Asterales. Springer, Berlin, pp 90-123

Leslie JF, Summerell BA (2006) The Fusarium laboratory manual. Blackwell, Oxford

Leyronas C, Chrétien PL, Troulet C et al (2018) First Report of Fusarium proliferatum Causing Garlic Clove Rot in France. Plant Dis 102(12): 2658

Pérez BA, Berretta MF, Carrión E et al (2011) First report of root rot caused by Fusarium proliferatum on blueberry in Argentina. Plant Dis 95(11): 1478

Terri TH, Elomaa P, Kotilainen M et al (2006) Mining plant diversity: gerbera as a model system for plant development and biosynthetic research. BioEssays 28:756-767

White TJ, Bruns T, Lee S et al (1990) Amplification and direct sequencing of fungal ribosomal RNA genes for phylogenetics. PCR Protoc Guide Methods Appl 18(1):315-322

Zhang J, Wu X, Bi Y et al (2013) First Report of Fusarium proliferatum Infecting Carnation (Dianthus caryophyllus L.) in China. J Phytopathol 161(11-12):850-854

Publisher's Note Springer Nature remains neutral with regard to jurisdictional claims in published maps and institutional affiliations. 